\title{
Odo Marquard: sobre la necesidad del pluralismo en los márgenes de la antropología filosófica y la filosofía política
}

\author{
María Cristina López Bolívar* \\ Recibido: 11 de febrero del 2018 \\ Enviado a pares evaluadores: 19 de marzo del 2018 \\ Aprobado por Comité editorial: 22 de abril del 2018 \\ https://doi.org/10.22395/csye.v7n13a7
}

\section{RESUMEN}

Odo Marquard, filósofo alemán de la posguerra de la Segunda Guerra Mundial, dedicó gran parte de su vida a escribir en innumerables ensayos sobre el origen de los estragos sociales, políticos y humanos que ocasionaron la realización de las utopías que tuvieron lugar durante los siglos XIX y $\mathrm{XX}$ y que desembocaron en los totalitarismos, tanto de izquierda como de derecha. Para este autor, el origen se encuentra en la eliminación de la pluralidad y el disenso propios de un mundo contingente, en el cual no es posible privilegiar una visión del mundo y del hombre, sino aceptar las múltiples concepciones del hombre y del mundo. La antropología filosófica y la filosofía política son herramientas fundamentales para dar cuenta de esta pluralidad que -reconocida desde los valores del civismo burgués de libertad e igualdad, y de la mano con una actitud escéptica- puede evitar el surgimiento de nuevos totalitarismos en el siglo XXI. En este sentido, más que actual, el análisis que se presenta en el ensayo sobre el pluralismo desde Marquard, puede aportar elementos críticos para un diagnóstico de las sociedades contemporáneas.

Palabras claves: pluralismo; hombre; escepticismo; antropología filosófica; filosofía política.

Magíster en Filosofía de la Universidad de Antioquia (Colombia) y filósofa de la misma universidad. Profesora de cátedra del Instituto de Filosofía de la Universidad de Antioquia y Profesora de la Universidad Tecnológica de Pereira (Colombia). Correo electrónico: cristina1856s@gmail.com 


\section{Odo Marquard: On the Need for Pluralism in Philosophical Anthropology and Political Philosophy}

\section{ABSTRACT}

Odo Marquard, German post- Second World War philosopher, devoted a significant part of his life to writing countless essays about the origin of social, political and human havoc caused by the concretion of utopias that took place during the $19^{\text {th }}$ and $20^{\text {th }}$ century, and that led to totalitarianism, both left and right. For Marquard, the origin lies in the abolition of plurality and dissent characteristic of a contingent world, one in which it is not possible to privilege an understanding of the world and men, and it is necessary to accept multiple conceptions. Philosophical anthropology and political philosophy are fundamental to account for this plurality that -recognized by the bourgeois citizenship values of freedom and equality, and hand in hand with a skeptical attitude-may prevent the emergence of new totalitarianisms in the $21^{\text {st }}$ century. In this sense, the analysis on pluralism form Marquard's point of view presented in this essay remains timely and may provide critical elements to diagnose contemporary societies.

Keywords: pluralism; men; skepticism; philosophical anthropology; political philosophy.

\section{Odo Marquard: sobre a necessidade do pluralismo nas margens da antropologia filosófica e da filosofia política}

\section{RESUMO}

Odo Marquard, filósofo alemão do pósSegunda Guerra Mundial, dedicou grande parte de sua vida a escrever, em inúmeros ensaios, sobre a origem dos danos sociais, políticos e humanos que ocasionaram a realização das utopias que ocorreram durante os séculos XIX e XX e que desembocaram nos totalitarismos, tanto de esquerda quanto de direita. Para esse autor, a origem está na eliminação da pluralidade e da divergência próprias do mundo contingente, no qual não é possível privilegiar uma visão do mundo e do homem, mas aceitar as múltiplas concepções do homem e do mundo. A antropologia filosófica e a filosofia política são ferramentas fundamentais para abarcar essa pluralidade que - reconhecida a partir dos valores do civismo burguês de liberdade e igualdade, juntamente com uma atitude cética - pode evitar o surgimento de novos totalitarismos no século XXI. Nesse sentido, mais do que atual, a análise apresentada no ensaio sobre o pluralismo a partir de Marquard pode oferecer elementos críticos para um diagnóstico das sociedades contemporâneas.

Palavras-chave: pluralismo; homem; ceticismo; antropologia filosófica; filosofia política. 


\section{Introducción}

Odo Marquard, en su libro Filosofía de la compensación (2001), postula que desde sus principios, el discurso político ha acogido en su seno diferentes posturas, movimientos y valores morales, pero también disímiles concepciones sobre el hombre. De ahí que para el exprofesor de la Universidad de Giessen, el discurso de la antropología filosófica está directamente relacionado con la teoría política. Para este autor, ambas posturas guardan un factor en común, a saber, el pluralismo que reconocen como necesario en las visiones compartidas que tenemos de nosotros mismos (antropología filosófica) y de la vida en sí (la esfera de lo político).

En este sentido, Marquard encierra una noción de pluralismo entendido como la diversidad de actores y opiniones a los cuales se les reconoce su importancia en la vida del hombre, pero a ninguno de ellos se le otorga preponderancia, aquella que llevará a cabo la división de poderes en la esfera pública. Con este pluralismo, reivindica su rechazo al totalitarismo por deslegitimar la necesidad del disenso propio e inherente a las sociedades democráticas. El objetivo principal del presente texto es conocer la apuesta por el pluralismo de Marquard que, como se expone a continuación, se encuentra dentro de los valores del civismo burgués. Para ello, se presenta su postura antropológica en torno a la comprensión del hombre. Seguidamente, se aborda el escepticismo como puente entre la postura antropológica y política marquardiana. Por último, se presenta el pluralismo político de este autor con relación a los valores del civismo burgués.

$$
-\mathrm{I}-
$$

La antropología filosófica es un área de la filosofía que enfatiza en la necesidad de estudiar al género humano. El humanismo surge en parte, como respuesta a esta necesidad que solo hasta la modernidad enfatiza en hablar del hombre desde la secularización del discurso filosófico, lejos de la teología, para reflexionar sobre él a partir de los diversos aspectos que lo atraviesan, es decir desde lo social, lo económico, lo cultural y la política, todos ellos elementos relevantes de aquello que se denominó en la filosofía ilustrada como mundo de la vida, del que hace parte el hombre "humano". Sin embargo, para decir qué es la antropología filosófica se necesita más que una reflexión escueta sobre la necesidad de estudiar al hombre en el mundo. Marquard lo sabe muy bien y así lo expone en el ensayo " $E l$ hombre de este lado de la utopía. Observaciones sobre la historia y la actualidad de la antropología filosófica", allí reflexiona con rigor sobre la necesidad de una antropología filosófica en el marco de un pluralismo político y antropológico.

Para Marquard la antropología filosófica fue, es y será relevante porque crea la posibilidad de estudiar al hombre en su pluridimensionalidad como ser 
perteneciente al mundo de la vida, es decir, al mundo real. Así, en gran parte de su texto se preocupa por el origen cronológico de la antropología filosófica. Esta inquietud se debe a una necesidad de entender a la misma como una reflexión de la filosofía moderna que se dedica a la comprensión del hombre humano que surge en Alemania y toma fuerza en 1772 cuando Kant, tras exponer todo su programa crítico de la razón, nombra dos extrañamientos frente al mundo del conocimiento.

El primer extrañamiento hace referencia a la metafísica que divaga y se pierde en los conceptos puros. El segundo es un extrañamiento frente a las ciencias naturales que solo se instituyen a partir del conocimiento experimental. Para Kant, ambos extrañamientos suscitan-a pesar de su puritanismo conceptual-un cuestionamiento sobre si efectivamente, los estudios y las reflexiones filosóficas y científicas tienen en cuenta al "mundo real", el mundo en el que el hombre humano, el hombre pragmático vive su vida.

Para Kant el conocimiento del hombre es conocimiento del mundo porque el hombre es una parte del mundo y en este sentido, el conocerse a sí mismo no difiere ni anula el hecho de conocer el mundo en el cual se habita. Por el contrario, para Marquard el conocimiento del mundo es conocimiento del hombre. Dar cuenta de las diferentes dinámicas que convergen en el mundo en términos políticos, sociales, económicos, etc., es a su vez, dar cuenta de un hombre humano constitutivamente plural. Para ambos autores, ya sea desde el conocimiento de sí mismo como conocimiento del mundo, o desde el conocimiento del mundo como conocimiento de sí mismo, se plantea una necesidad "pragmática" -dice Kant- de conocer al hombre desde "el mundo real", desde sus rutinas cruzadas por los diversos aspectos que configuran la vida, y desde allí, se habla del hombre humano en términos de pluralismo. En otras palabras, reconocer la pluralidad del mundo o la pluralidad del hombre es reconocer el pluralismo inmanente del mundo real.

En el mundo real -el mundo del hombre humano- es importante tener en cuenta un horizonte de apertura que nunca se cierra y que se alimenta de la pluralidad de historias que narra el hombre, no solo aquel activo sino también el "sufriente", el hombre "deficitario" o "sin esencia"1 para quién es necesario que la historia permanezca abierta y atenta a los cambios que generan los diferentes sentidos de la vida del hombre humano. De este horizonte de apertura se encarga la antropología filosófica (sin que esta sea su única o principal función), de presentar el "carácter dudoso" del hombre que se cuenta y da cuenta de sí en las diferentes dimensiones que atraviesan al mundo real, o en palabras de Marquard, "[...] en las variadas configuraciones de la cultura" de las que no da

Marquard menciona que estos términos recogen los aspectos claves en las diferentes concepciones humanistas sobre el hombre (Marquard, 2007, p. 97). 
cuenta una filosofía de la historia embebida en el progreso como objeto último de cualquier análisis histórico" (Marquard, 2001, p. 97).

La antropología filosófica de Marquard es una "antropología filosófica del desencanto", no un estudio objetivista de lo que "sí y solo sí" es el hombre, sino de las posibilidades de ser que -en cuanto hombre que participa en un mundo plural- se encuentran en el mundo real. Estas posibilidades están ligadas, no a un horizonte utópico de perfeccionamiento del hombre, pero sí a presentar y estudiar las posibilidades de que el hombre "escape de sus defectos". Para la antropología filosófica el hombre humano es "un chapucero", un remiendo de ensayos y errores, errores y más ensayos, que hace una cosa en lugar de la otra y que puede hacer una cosa en lugar de la otra. Así, la antropología según Marquard es:

[...] la antropología del 'en vez de'. Así -y en tanto rebelión contra el rechazo de la civilidad- es la antiutopía. Un fantasma recorre Europa (y agregaría que el mundo): el fantasma de la absoluta utopía sedienta de realización. Contra los fantasmas -precisamente contra aquellos que preparan su próximo aquelarre- hay un único remedio: la ilustración, y contra el peligro de una recaída en las pretensiones utópicas absolutas, la antropología filosófica. (Marquard, 2007, p. 126)

Para Marquard resulta importante la antropología del "en vez de" que presenta "el carácter dudoso" del hombre humano presente en el mundo real. Aquí es cuando la antropología se cruza con la filosofía política pues, ante las utopías socialistas que según el autor, fueron el germen de los totalitarismos del siglo XX, la antropología filosófica responde con un pluralismo bastante escéptico, porque ya ha podido dar cuenta de los estragos que causan las utopías autoritarias al mundo real cuando tratan de desterrar el "en vez de" para perpetuar un único horizonte de sentido y comprensión sobre el hombre y el mundo.

En pleno rechazo de la autoridad absoluta que supone un sentido unidimensional del mundo, no es posible entender la antropología filosófica como ciencia integral o como estudio dominante sobre el hombre humano, ya que como dice el autor:

[...] La realidad del ser humano es predominantemente lo contingente. Contingente es lo que podría ser de otra manera: La realidad del hombre, el hombre mismo como ser real es contingente, es casualmente de un modo y también de otro [...] esta diversidad es la oportunidad para la libertad humana: es aquella posibilidad de libertad la que hace valer la doctrina de la división de poderes; pues el efecto político liberador de la división política de poderes es solo un caso especial del efecto liberador de la diversidad general de la realidad. [...] Montesquieu hace valer la división política de los poderes legislativo, ejecutivo y judicial solo como garantía de la libertad política; pero hay que tener en cuenta que Montesquieu [...] se encontraba en la tradición moralísitica, y esta es la tradición del escepticismo. (Marquard, 2005, p. 143) 
La antropología del "en vez de" es la realización del escepticismo que valida la división de poderes como consecuencia del reconocimiento del pluralismo en concordancia con la vida. Dicho reconocimiento debe ser protegido en los márgenes de una democracia porque, siendo antiutópica, no apela a ni reivindica una concepción del hombre y el mundo, sino que legitima los diálogos, los disensos y consensos propios del mundo real, un mundo diverso y contingente.

No hay valores absolutos para el escéptico, así mismo, tampoco los hay para la antropología filosófica como comprensión plural del hombre y del mundo. Abierta a los diálogos, no busca consensos, por el contrario, funciona como toda postura pluralista. Marquard rescata el momento del disenso de estos diálogos en los cuales la antropología filosófica es tan relevante, proveniente de una tradición filosófica con diferentes concepciones de lo que es el hombre, soporta y acoge con mejores herramientas el disenso del cual, no solo se enriquece sino que ayuda a "catalizar" u a orientar en el desarrollo mismo de los diálogos, tan bifurcados pero todos acogidos bajo los estudios del hombre humano en el "mundo de la vida".

Es significativo recordar al hombre del mundo real siempre, al hombre en concreto, más acá de determinaciones conceptuales u consideraciones experimentales, sumergido en la contingencia. Ese hombre que habita el mundo real o la contingencia, ese, o mejor, este hombre humano, presente en el mundo "sin esencia" y "deficitario" es el hombre "dudoso" del cual habla la antropología del "en vez de". Así las cosas, se vuelve relevante entender y tener presente la antropología filosófica marquardiana no como una comprensión unidimensional del hombre sino como un estudio o entendimiento del hombre sin horizontes históricos determinados y definidos, los suyos son abiertos, plurales y propios de una sociedad que puede construirse desde los valores del civismo burgués de libertad e igualdad que, en pleno reconocimiento de la contingencia, se construye de espaldas a cualquier germen utópico de autoritarismo y en aras de una democracia parlamentaria, como se explica al final de este texto.

En pos de aclarar un elemento fundamental del discurso del profesor de Giessen cabe preguntarse ¿qué entiende Marquard por contingencia?

$$
- \text { III - }
$$

Para Marquard el problema de la contingencia es un problema ético, repercute directamente en el comportamiento de las personas. Se entiende por contingencia todo aquello que puede ser de otra manera, incluso las elecciones de las personas que se consideraban pilares de un direccionamiento ético de las sociedades modernas que, como se ha demostrado a lo largo de la historia de 
la humanidad, pueden cambiar. En este sentido, la contingencia es transversal a la vida, inherente a una naturaleza cambiante y evolutiva. Para Marquard la aceptación de la propia contingencia no es arbitraria sino que supone la aceptación consciente de saberse finitos. En sus palabras:

Ciertamente, el concepto finito de lo contingente, que procede de la teología cristiana de la creación, se refiere a "lo que podría ser de otra manera". Pero tiene dos variantes si, en vez de mirarlo desde Dios, lo miramos (más humanamente) desde el ser humano. O bien lo contingente es "lo que podría ser de otra manera" y lo que por tanto podemos cambiar (por ejemplo, este discurso que yo podría haber pronunciado así o de otra manera): Se trata pues de lo contingente por arbitrariedad. O bien lo contingente es "lo que podría ser de otra manera" y no lo podemos cambiar, o solo poco (el golpe del destino que se resiste a su negación: por ejemplo, haber nacido): Se trata pues de lo contingente por destino. [...] De aquí se sigue que los seres humanos somos siempre más nuestras contingencias (nuestras contingencias por destino) que nuestras realizaciones. No esto[y] diciendo que seamos solo nuestras contingencias, digo únicamente que no solo somo[s] nuestras realizaciones [...] (Marquard, 2000, p. 24)

Quién está dispuesto a dudar como Marquard, de las determinaciones que sedimentan la vida en un único sentido, o en otras palabras, quien está dispuesto a aceptar la contingencia llegará al escepticismo, tal como lo señala en la conferencia antes citada. Pero el escéptico no suprime el hábito, tampoco niega la libertad. El escéptico no desprecia sus tradiciones, sabe que son parte constitutiva de su mundo, aquellas le permiten resguardarse de la impredecible contingencia al crear rutinas mediante las cuales da cuenta de su libertad para elegir qué hacer y cómo actuar. Se podría entonces interpretar que la libertad queda relegada por un relativismo valorativo producto de la contingencia, mas sucede todo lo contrario; la libertad se cultiva en la contingencia-como se explicaba anteriormente- en cuanto esta permite reconocer como pilar fundamental del mundo de la vida, la pluralidad y diversidad que habita al hombre, una pluralidad que si bien reivindica la división de poderes para Marquard, se entiende ella misma como el reconocimiento de diversas maneras de ver y vivir en el mundo, lo que permite el encuentro, la diversificación y el disenso de las múltiples posturas políticas.

En este sentido, me gustaría aclarar que para un escéptico como el autor alemán, la vida no está determinada porque es contingente, porque es una incertidumbre constante que no liga al hombre a un determinismo histórico o a una "locomotora" que guíe su trasegar, tanto individual como colectivo.

Para Marquard es muy importante tener en cuenta una "dietética", un moderamiento de las aspiraciones propia de las personas de la modernidad tardía caracterizada por la falta de sentido vital, para que esta no permita revivir la utopía revolucionaria de un tiempo mesiánico. Para que de pie a vivir 
el pluralismo presente y necesario para sostener los valores del civismo burgués de libertad e igualdad como los únicos que han podido frenar las aspiraciones totalitarias que se esconden tras una postura utópica, como en el caso de la Alemania Nazi, tema que le preocupa significativamente por su cercanía vital con este periodo histórico.

La interdisciplinariedad da cuenta de la aceptación de la contingencia como diversificación de lo que es y puede ser el hombre y la vida. De aquí que la antropología filosófica y la filosofía política sean los soportes del pluralismo. Ambas disciplinas distinguen las diferentes maneras der ser y vivir en el mundo y permite la participación de actores antagónicos en aras de la armonía social.

Así, otro de los aspectos a resaltar es que no se debe caer en idealismos teóricos que se vuelvan predilectos a la hora de realizar alguna práctica política en la cual el pluralismo -constitutivo y sobresaliente en el ejercicio de la opinión pública-se censure. El profesor alemán dice que no se trata aquí de "fomentar un entusiasmo revolucionario", sino de que el objetivo principal de cualquier concepción que ose llamarse a sí misma pluralista, tiene que ser el de "responder urgentemente a la vida cotidiana". De aquí que para Marquard sea tan importante el civismo burgués en el marco de un discurso político pluralista, pues es este mismo el que representa al hombre plural producto de la contingencia "en el mundo de la vida". Empero, no basta el civismo para exponer en el mundo a un hombre plural.

Para Marquard los estudios interdisciplinarios son importantes porque permiten asistir al mundo de diversas maneras, con diversas perspectivas que acentúan la relevancia del pluralismo. En este sentido es importante que no impere ninguna postura sobre las otras, que desde el pluralismo y con el mismo se garanticen las comprensiones múltiples sobre la vida, incluso en la academia.

Nótese que la postura marquardiana no solo va del discurso al discurso, sino del discurso a la práctica, a la vida cotidiana; hace del pluralismo, la incertidumbre escéptica y de la contingencia, la reafirmanción de cierta aversión contra los totalitarismos provocados en el siglo XX y que desdibujaron la idea del hombre como sujeto libre. En Marquard la división de poderes es la "garantía" para que escenarios distópicos y totalitarios no vuelvan a surgir, ya que reconoce lo necesario que es el disenso para la consolidación de la comunidad política.

El desacuerdo, el mirar los objetos desde diferentes ópticas es lo que también permite construir -desde los valores republicanos del civismo burgués- a la sociedad civil. 
A lo mejor como lo expone Marquard, "el antiquísimo vicio de los filósofos -su crónico déficit de consenso-" también sea en este tiempo, la principal virtud de un régimen político y sea necesario para una interdisciplinariedad académica efectiva.

$$
-\mathrm{V}-
$$

Antes de continuar con la dilucidación de la última parte de este ensayo, quiero resaltar una postura que está presente en Marquard y que no se ha aclarado lo suficiente en este texto, me refiero a la figura del escéptico, que en palabras del autor, se define de la siguiente manera:

En el libro de 1957 Helmut Schelsky distingue [...] la generación escéptica: desilusionada, desengañada, antiideológica y precisamente por eso especialmente apta para sobrevivir. Yo formo parte de esa generación escéptica: no soy muy apto para la supervivencia (¿quién puede serlo, y a la vez ser filósofo?), pero sí soy escéptico. Y el escepticismo de la generación escéptica [...] fue la respuesta directa, expresa y plenamente racional al totalitarismo nacionalsocialista y sus crueles consecuencias. Y formaba parte de este escepticismo el que uno no quisiera dejarse persuadir por algún totalitarismo nuevo. El fiat utopia, pereat mundus se hizo sospechoso en todas sus formas. Mi propio escepticismo (y el escepticismo es, en efecto, la seña de identidad de mi filosofía) es el susto convertido en posición teórica, la desilusión convertida en posición teórica. La experiencia fundamental está expresa en este principio: puedo equivocarme [...] los otros también. (Marquard, 2005, p. 30)

El escepticismo marquardiano no es solo una apuesta teórica sino vital que se declara abiertamente contra las utopías. Duda y cuestiona las mismas por los estragos que ocasionaron en el siglo XX. A lo que apunta es a adoptar una actitud crítica frente a la vida y en cada acontecimiento de la esfera pública que pueda desembocar en un totalitarismo.

¿Por qué la apuesta de Marquard desde el escepticismo y pluralismo lleva al civismo burgués?

Para este autor la apuesta por el civismo burgués, más que ser la consecuencia del pluralismo y el escepticismo, es la garantía para que estos dos preceptos se desarrollen social, interdisciplinaria y políticamente, de la mano con una comprensión antropológica abierta a múltiples interpretaciones sobre lo que es el hombre. Sin embargo, la necesidad de desarrollar el pluralismo y el escepticismo se encuentra en el hecho de que estos -dentro de los parámetros del civismo burgués- son los que pueden evitar la configuración de la utopía en un régimen totalitario. Cabe anotar de manera crítica que, a pesar de todos los entuertos del civismo burgués -como la configuración de un Estado débil que cede ante las presiones del mercado-, las críticas que socialistas como Marx, libertarianos como Nozisck y anarquistas como Bakunin le han realizado al mismo, no es fácil 
desterrarlo de la esfera política, ya que parece que su ideología sigue siendo la única capaz de pervivir gracias a que acepta las diferencias y no intenta homogeneizar a los hombres bajo un ideal mesiánico.

El origen del argumento marquardiano no es práctico, pese a que se encuentra en el epicentro de sus consideraciones en torno a la Segunda Guerra Mundial, sino teórico, puesto que va desde la huida del "tener conciencia" al "ser conciencia".

Los actores de la posguerra sufrieron el señalamiento del mundo que los culpaba de complicidad por su anomia social ante los trágicos acontecimientos o peor aún, por su participación -aunque fuese pasiva-en los mismos hechos. Así, la vergüenza colectiva se sumaba al hambre y la miseria de las sociedades de la posguerra, las cuales soportaban en aras de expiar su culpa, el señalamiento y la hambruna a la que eran sometidos, o bien por la contingencia o bien por la comunidad internacional. Pero, como dice Marquard, la culpa y la vergüenza son insoportables y en la década de 1960 se popularizó la crítica como "[...] el más exitoso mecanismo de descarga, y su figura fundamental fue esta: uno se sustrae al tribunal al convertirse él mismo en el tribunal, Se huyó del tener conciencia hacia el ser conciencia".

La mala conciencia sobre sí mismo se superaba al volverse mala conciencia de los demás. Esto explica el por qué los años de la posguerra son aquellos en los cuales Alemania ha producido más intelectuales críticos ${ }^{2}$. El lema "nunca más nacionalismos" se radicaliza hasta convertirse en el "nunca más identificación", como lo señala el profesor alemán, que justifica así y nuevamente, no solo su escepticismo, sino "el no" que se da a las utopías después de un siglo de desenlaces trágicos de las utopías en Europa; como un "no" producto que llega desde un pasado para instalarse a manera de compensación, resistencia y rechazo a las tiranías que negaron el civismo burgués en aras de la igualdad social. Para el autor:

La negación del civismo burgués es el mal que hay que combatir si se quiere combatir el totalitarismo; y esto no puede hacerse mediante la negación del civismo burgués, sino solo mediante lo contrario a esto: comprometiéndose con ese civismo, con la democracia liberal parlamentaria de la República Federal. La República Federal no es una revolución malograda: precisamente porque es una república burguesa. El entusiasmo por las dictaduras antiburguesas (de derechas y de izquierdas) es nocivo. Hay que tornarlo políticamente superfluo reforzando políticamente el centro político, sobre el que luego se puede discutir si es preferible que sea un centro reformista o un centro conservador: La democracia parlamentaria dispone de procedimientos que permiten resolver esta discusión. [...] lo conveniente no es la negación del civismo burgués, sino negarse a negar el civismo burgués. Esto es lo que yo aprendí en 1945 y después de 1945. (Marquard, 2005, p. 36)

2 La escuela de Frankfurt es prueba fehaciente de ello. 


\section{Conclusión}

En síntesis y según Marquard, en el marco de una democracia parlamentaria como aquel que reconoce la libertad del hombre y las diferentes concepciones de vida que devienen del ejercicio de la misma, el civismo burgués es necesario como fundamento de resistencia contra las sociedades políticas que, producto de las utopías, llegaron o pueden llegar a ser totalitarias. Cabe advertir que el diagnóstico sobre las utopías que presenta el autor no se da únicamente en clave política. La necesidad de la antropología filosófica como reconocimiento de hombres con diferentes visiones del mundo y de la contingencia, se expresa en el estudio del hombre sobre sí mismo como ser libre. Este estudio de un hombre plural debe darse en clave de interdisciplinariedad, pero sobre todo, ha de tenerse en cuenta en la construcción de una comunidad política que establezca la división de poderes como garantía a la afirmación de la libertad y pluralidad en torno a la vida de los hombres. Todo esto de la mano de un escepticismo político y vital.

\section{Referencias}

Kant, I. (2004). Antropología en sentido pragmático. Madrid: Alianza.

Marquard, O. (2000). Apología de lo contingente. España: Katz.

Marquard, O. (2001). Filosofía de la compensación. Escritos sobre antropología filosófica. Buenos Aires: Paidós.

Marquard, O. (2005). Individuo y división de poderes. España: Trotta.

Marquard, O. (2007). Felicidad en la infelicidad. España: Katz. 